\title{
A Study of Geographical Indication (GI) System for Food Stuffs in India
}

\author{
Dr Sandip S Tapkir \\ Head -Ajeenkya D Y Patil University School of Hotel Management, Charholi BK Pune Mah India.
}

\begin{abstract}
India being known for its oldest civilization with its rich culture and tradition with special emphasis toward food and culture. We find much diverse food and culture in its gastronomical study. Although, food stuff contributing only $3.9 \%$ of registered GIs. Special attention need to be given by the stake holders (public and private).

The present research paper attempts to look into the status and system of GI and trade practices in food stuff. This is to highlight the role of GIs to protect the importance of origin of food stuffs and its culture and tradition.

Further these GI food tags are pride of Indian cultural diets, extensively followed by the world. The majorities of food stuffs are unidentified and legally unprotected and the consumers are also not aware of the same. This is to give brief indication about how GI considerations of pursuing and protecting Indian Food stuff is essential and we must give attention to register maximum food stuffs to protect originality of the food and culture which is necessary to do so.
\end{abstract}

Keywords:- Geographical Indications, Food Stuffs.

\section{INTRODUCTION}

The GI tagging system is very less adopted by the Indian businesses and entrepreneurs. That is why we find very less GI tagging product or services registered so far in India. As far as food is concern there is huge opportunities to undergo for the GI tagging, a number of traditional and original food stuffs we have in India. Both public and private players need to secure the originality of the food stuffs. Since Indian food is very much demanded across the globe, it is very much advisable to register maximum Indian food under this GI tagging system.

This G. I. Act (Registration and Protection) has enforce on 15th September 2003. G.I. Act descries the goods belongs to agricultural, natural goods or manufactured goods suitable to apply to G.I. tag. Geographical Indication office located at Chennai and the registrar of the office takes care of all GI application. GI protection is given for ten years which can be renewed.

\section{LITERATURE REVIEW}

\section{Number of GI tags in India}

India has 320 products as given GI status. Among the products listed there are Tirupati Laddu, Kangra Paintings, Nagpur Orange, Darjeeling Tea, and Kashmir Pashmina. In India, Karnataka has 38 G.I. products, Maharashtra which has 32 G.I. products.

\section{$>$ Advantages of GI tagging:}

- Legal Status and security to G.I. in India;

- Safe guards to unauthorized utilization of an enlisted geographical indications by others;

- Preserves origin of the product and protection in other WTO part nations.

- For marketing and branding of the product and services.

\section{$>$ Current status of G.I.}

India has 301 GI products registered so far and over 270 more products have applied for the label. India has major G.I. share in the Handicrafts, Agriculture, Manufactured items, Foodstuff products have to improve on the G.I. registrations.

\section{OBJECTIVE OF THIS STUDY}

$>$ To analyze the current status of the food stuffs registered under geographical indication in India.

$>$ To highlight the necessity and importance of GI tagging for the Food Stuffs in India.

$>$ To know the process of GI tagging in India.

$>$ To spread the awareness about GI tagging for Food Stuffs.

\section{RESEARCH METHODOLOGY:}

The study is on secondary data. This data is collected from various governmental and official organizations such as World Trade Organization, the World Intellectual Property organization and Geographical Indications Registry (Intellectual Property India). There are some research paper did studied for the same. There is few news articles in the magazines and newspaper also referred as part of data. Although, we found very less study and research on this subject available for the references. 


\section{Food Stuff in G.I. in India:}

\section{GI Food stuffs}

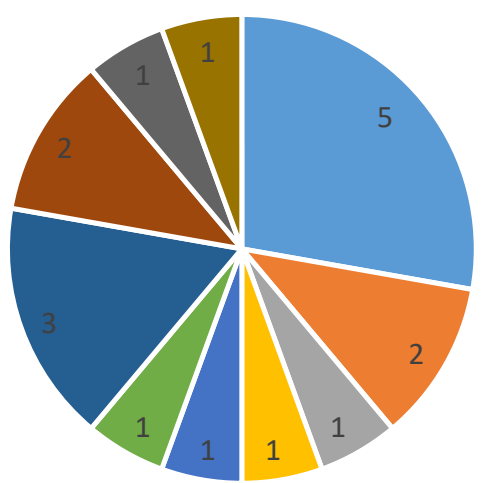

$$
\begin{array}{ll}
\text { - Bengal } \square \text { Andra } & \text { - Telangana } \\
\text { - MP Rajastan } & \text { - Karnataka }
\end{array}
$$

Fig 1

List of the Food Stuffs with G.I. tagging in India:

\begin{tabular}{|c|c|c|c|}
\hline SN & FOOD STUFF & STATE ORIGIN & REMARK \\
\hline 1 & Darjeeling Tea & Assam & Tea \\
\hline 2 & Cashew Feni & Goa & Sountry liquor status \\
\hline 3 & Tirupati Laddu, & Andhra Pradesh & Coffee beverage \\
\hline 4 & Monsoonal Malabar Coffee, & Kwarnataka & Salty \\
\hline 5 & Odissa Rasgulla & Odissa & Dish \\
\hline 6 & Ratlami Sev MP & Telangana & Fruit \\
\hline 7 & Hyderabad Haleem & Maharashtra & Salty \\
\hline 8 & Nashik Valley Wine & Maharashtra & Sweet \\
\hline 9 & Mahabaleshwar Strawberry & Rajasthan & Sweet \\
\hline 10 & Bikaneri Bhujia & Bengal & Chicken meat \\
\hline 11 & Bardhaman Sitabhog (Food) & Madhya Pradesh & Sweet \\
\hline 12 & Joynagar Moa (Food) & Andhra Pradesh & Sweet \\
\hline 13 & J Kadaknath Black Chicken Meat & Karnataka & Sweet \\
\hline 14 & Bandar Laddu & Bengal & Sweet \\
\hline 16 & Dharwad Pedha (Food) & Bengal & Sweet \\
\hline 17 & Banglar Rasgulla & Bengal & \\
\hline
\end{tabular}

Table 1

Classification of goods-Name of the classes:

There are 34 classes of the G I tagging including various sectors such as manufacturing, agriculture, handicraft, chemicals, Pharmaceutical, medical. Musical, household materials and many more.

For food stuffs we have seen class 29 to 32 and for beverages classes from 33 to 34 . 


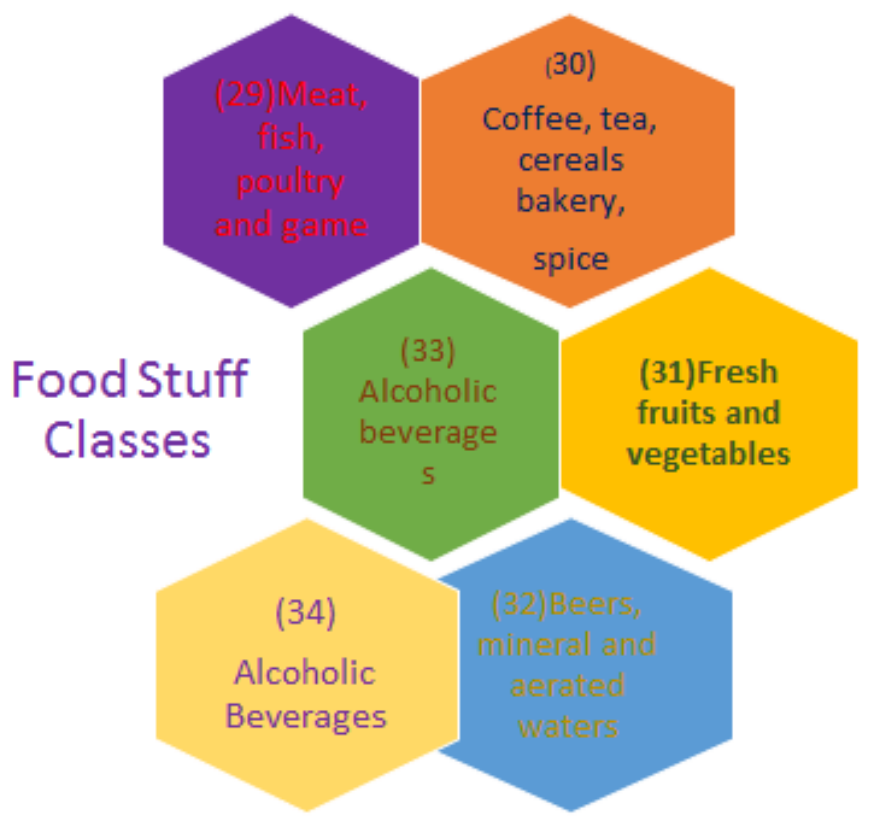

Fig 2

A Copy of GI Tag for Rasgulla:

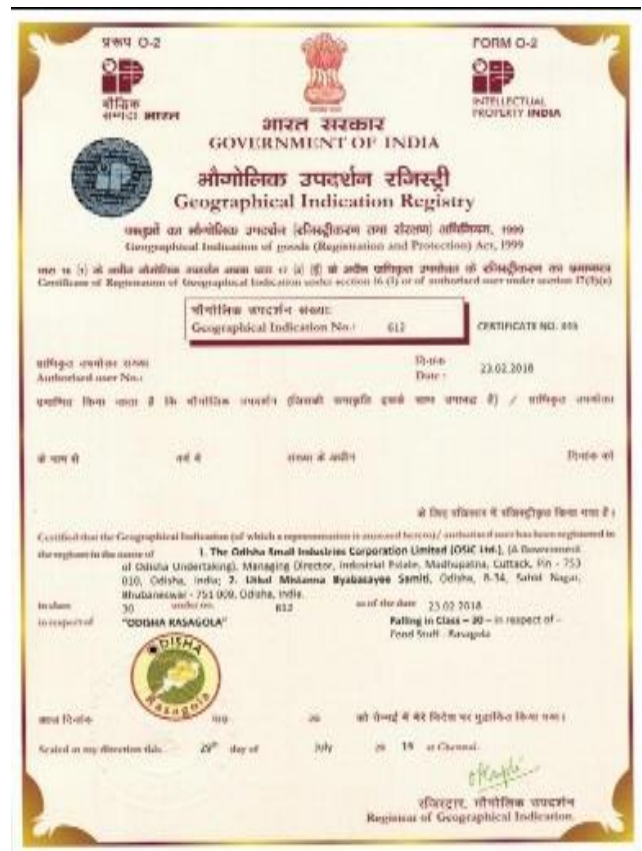

Fig 3

\section{CONCLUSION}

This entire exercise was to understand the status of food stuffs tagging so far in India and also to know the system of food stuff tagging. There is a huge task and many food stuffs uncovered and unprotected. There are thousands of traditional food stuffs in India, only but only few are in existence today. We need to utilize the situation for growing demand for Indian traditional food across globe. There is a huge demand for Indian traditional food. GI tagging will protect the origin of our recipes and food stuffs and also helpful to generate employment for Indian food. It will be benefitted to all small regional scale eateries and food outlets.

Major benefit of G.I. protection from the producers' point of view, food processing and exporting the same to the world is growing; it will help to generate revenue to country and its economy.

There are many food stuffs like Rasgulla, Misthi dahi, Mysore pak, Agra petha, Chhana podo, Goan feni could preserve the identity and protect from geographical indication law. 
India, primarily an agricultural economy with social, cultural, ethnic, food diversities, having thousands of products that would need for a geographical indication.

However, the impact of GIs is to protect the Producer's rights and preservers their interest of the products whether the benefits reaches to the real people or not. In short there is a huge work and task remains covered specific to food stuff GI tagging.

As a research person we all need to take this task ahead and maximum food stuffs need to be under G.I. tagging to protect the origin of the same.

\section{RECOMMENDATION}

GI tagging is an essential to protect the original rights of the food stuffs, it is advisable to all food concern people or businesses to register their product.

$>$ All government agencies related to food stuffs must act sincerely and seriously to protect our food stuffs registering the GI tag.

$>$ We need more research and study on the same topic in our Hotel management or culinary institute to focus on the subject.

We all need to bring forward Indian gastronomical identity by exploring more and more traditional foods from all parts of the country.

\section{REFERENCES}

[1]. Anonymous, 2009. Geographical Indications Journal No. 31, GI Application Number 142 http://ipindia .nic.in/girindia/journal/Journal_31.pdf7

[2]. Broude, T. 2005. Taking 'Trade and Culture' Seriously: Geographical Indications and Cultural Protection in WTO Law. Journal of International Economic Law. 26:624-692

[3]. Dewan, M. 2011. IPR Protection in Agriculture: An Overview. Journal of Intellectual Property Rights. 16:131-138

[4]. Indian Food Industry. (2014). http://www.ibef.org/ artdispview.

[5]. Kornel, D., Mohapatra, S.C. and Acharya, R.M. 2006. Sheep and goat genetic resources of Orissa: A survey report with government of Orissa. Indo-Swiss Natural Resource Management Programme, Orissa

[6]. Nanda, D.K., Singh, R., Tomar, S.K., Dash, S.K., Jayakumar, S., Arora, D.K., Chaudhary, R. and Kumar, D. 2013. Indian Chilika curd - A potential dairy product for Geographical Indication registration. Indian Journal of Traditional Knowledge,

[7]. Rangnekar D. 2004. The Socio - Economics of Geographical Indications. ICTSD - UNCTAD project on IPRs and Sustainable Development. Geneva.

[8]. Ravi, V. 2003. Protection of GIs in India. Presented at WIPO Asia Pacific Symposium on GIs, Delhi, 18-20 November
[9]. Tea Board of India, 2010. 'Darjeeling Tea - The Best'

http://www.teaboard.gov.in/inner1.asp?param_link_id $=62010$

[10]. TOI, the Times of India 2009. Tirupati Laddu gets global patent http://timesofindia.indiatimes.com /India/Tirupati-Laddu-gets-global-patent/articleshow 15015694.cmsIndian Geographical Indicators for Food,

[11]. Swati Sharma: Geographical Indication In India: Current Scenario And Their Product Distribution, International Journal Of Social Science And Economic Research, Issn: 2455-8834Volume: 04, Issue: 04 "April 2019"

Sources:

[12]. https://www.legalindia.com/question/what-is-theregistration-procedure-for-gi/

[13]. https://www.wto.org/english/res_e/booksp_e/casestudi es_e/case16_e.htm

[14]. https://en.wikipedia.org

[15]. www.researchgate.com

[16]. http://ipindia .nic.in/girindia/journal/Journal_31.pdf7 